\title{
Waun Ki Hong, MD, D.M.Sc (Hon) (1942-2019): A Mentor Who Left Behind a Legacy for Generations to Come
}

\author{
Hyun Cheol Chung \\ Division of Medical Oncology, Department of Internal Medicine, Yonsei Cancer Center, Yonsei University College of Medicine, Seoul, Korea.
}

\section{FORGING A LANDMARK CAREER}

Professor Hong was born on August 13, 1942 as the sixth of seven children, while Korea was still under Japanese colonial rule. He credits his late brother, Suk Ki Hong, MD, PhD, a professor at New York State University who used to be a chair of the Department of Physiology at Yonsei University College of Medicine and made significant scientific contributions in renal physiology and diving medicine, for influencing Professor Hong to pursue a career in medicine. ${ }^{1}$ He received his medical degree in 1967 from the Yonsei University College of Medicine in Seoul. When Professor Hong and his wife, Mihwa, who was 8 months pregnant at the time, made the journey from Korea to Manhattan, New York in 1970, he had just $\$ 451$ in his wallet, and the only job he could get was as an intern at the Bronx-Lebanon Hospital Center, a community hospital in the Bronx. ${ }^{1}$

Working as an intern was grueling-24-hour shifts every two nights-and his lack of proficiency in English made it difficult to communicate clearly with his patients and members of the hospital staff. After completing his internship, he applied to hundreds of hospitals in the state but received few responses, obtaining only one letter of recommendation from an orthopedic surgeon he had assisted during surgery by holding clamps for 5 to 6 hours. The surgeon wrote a two-paragraph letter which essentially stated that "this guy assisted with my opera-

Received: May 20, 2020 Accepted: May 21, 2020

Corresponding author: Hyun Cheol Chung, MD, PhD, Division of Medical Oncology, Department of Internal Medicine, Yonsei Cancer Center, Yonsei University College of Medicine, 50-1 Yonsei-ro, Seodaemun-gu, Seoul 03722, Korea.

Tel: 82-2-2228-8132, Fax: 82-2-393-3652, E-mail: unchung9@yuhs.ac

-The author has no potential conflicts of interest to disclose.

(c) Copyright: Yonsei University College of Medicine 2020

This is an Open Access article distributed under the terms of the Creative Commons Attribution Non-Commercial License (https://creativecommons.org/licenses/ by-nc/4.0) which permits unrestricted non-commercial use, distribution, and reproduction in any medium, provided the original work is properly cited. tions and is very strong at holding clamps." Professor Hong said this might have been pretty discouraging to most people, noting that he had to continue applying for almost a year before landing a residency at the Boston Veteran's Affairs (VA) Medical Center. However, during residency at the Boston VA Medical Center, Professor Hong found his calling in oncology. He said, “I realized that I wasn't that good. I experienced major hardships, especially during my first 3 years as a foreigner. I had to overcome language and cultural barriers. It was tough. Fortunately, I was tough enough to overcome the challenges in the environment."1 In Professor Hong's view, there is no hopelessness, only hope. After deciding to specialize in oncology, he was accepted into a fellowship program at the Memorial Sloan Kettering Cancer Center (MSKCC), where his mentors included Burton Lee, MD, Irwin Krakoff, MD, and Robert Wittes, MD. ${ }^{2}$ It was while at MSKCC that he developed a passion for research and academia-two professional loves that would become the cornerstones of his work. After finishing his fellowship in 1975, he returned to the Boston VA Medical Center as the Chief of Medical Oncology, where his original mentor, Dr. Joel Caslowitz, was present, and became a faculty member at both the Boston University School of Medicine and the Tufts University School of Medicine. He established one of the best medical oncology programs in Boston, which comprised 13 board-certified medical oncologists. He led the landmark Veterans Administration Cooperative Laryngeal Cancer Study Group's induction chemotherapy and radiotherapy trial for laryngeal preservation, which changed the way the disease is managed and served as a model for organ preservation for many other types of cancer. ${ }^{3}$ The study results were published in The New England Journal of Medicine (NEJM) in 1991. "I learned the larynx preservation technique from my mentor at MSKCC, Robert Wittes, MD, so I have to give him credit," said Professor Hong. "I was always behind; I started at the bottom. However, it is not important who starts first. It is important 
who finishes first," he added. Professor Hong noted that, of the 14 members in his fellowship program, he was the first to become a full professor at the age of 42 years. Thus, he beat the odds of his cohort. ${ }^{1}$

\section{USHERING IN A NEW ERA OF PERSONALIZED MEDICINE}

In 1984, Professor Hong was recruited by Irwin H. Krakoff, $\mathrm{MD}$, head of the Division of Medicine at MD Anderson Cancer Center (MDACC) and a mentor during his fellowship training at MSKCC. Professor Hong stayed at MDACC for the next 30 years, serving as the chair of the Thoracic/Head and Neck Medical Oncology Department, head of the Cancer Medicine Division, and the Vice Provost for Clinical Research. It was at MDACC that Professor Hong began a new historical chapter in his work after realizing the power of multidisciplinary research and of having access to high-quality scientific collaborators. ${ }^{4}$ With the support of the National Cancer Institute in 1986, he established a large multidisciplinary research program to focus on chemoprevention in the aerodigestive tract. ${ }^{5}$ This project published research results in 1986, 1990, 1993, and 1995 in NEJM, contributing to defining a new discipline in cancer prevention and cancer interception strategy. In 2004, he developed a new paradigm of personalized cancer therapy with his work on the landmark Biomarker-integrated Approaches of Targeted Therapy for Lung Cancer Elimination trial, which ushered in a new era of precision medicine. ${ }^{1}$

As the head of Cancer Medicine, Professor Hong supervised 17 academic departments and more than 350 faculty members. He established a premier cancer medicine program across the board, training more than 200 clinical fellows. "To survive in academia, you have to have a passion, resilience, perseverance, and patience," explained Professor Hong. ${ }^{6}$ He transformed MDACC into a hotbed of collaborative translational research and, as part of his legacy, MDACC today boasts an enormous patient volume; magnificent cutting-edge, biomarker-driven translational trials; more federal funding in cancer than any other institutions over the last decade; and a rich pipeline of exceptional physician-scientists. ${ }^{2}$ He played a leadership role in shaping public policy through his service as the chair of the Prevention, Clinical, and Therapeutic Subcommittee for the National Cancer Institute (NCI) External Board of Scientific Advisors (BSA); the NCI Translational Research Working Group; the United States Food and Drug Administration Oncologic Drug Advisory Committee; and the Subcommittee of Clinical Investigations for the National Cancer Advisory Board. He was appointed by President George W. Bush to serve on the National Cancer Institute's National Cancer Advisory Board, and was also elected as a member of the U.S. National Academy of Medicine. Similarly, he was also made a member of the National Academy of Medicine in Korea. Ap- pointment as an elected member to the Institute of Medicine (IOM) of the National Academies is considered one of the highest honors in the fields of health and medicine, and it recognizes individuals who have demonstrated outstanding professional achievements and commitment to service. Professor Hong has been recognized with numerous awards, including the Medal of Honor for Clinical Research from the American Cancer Society, the Raymond Bourgine Award and the Claude Jacquillat Award from the International Congress on Anti-cancer Treatment in France, the Joseph A. Burchenal and Rosenthal Foundation Awards from the American Association for Cancer Research (AACR), the David Karnofsky Memorial Award from the American Society of Clinical Oncology, the Expatriate Award from the Korean Broadcasting System, the HoAm Prize in Medicine from the Samsung Foundation, the Proud Korean Award from the Korean American Leadership Foundation, the Proud Alumni Award from Yonsei University, and a Lifetime Achievement Award from the Korean American Medical Association. He served as the first-ever Asian-American President of the AACR (2001-2002) and as an inaugural fellow of the AACR academy. ${ }^{6}$ He said, “If you don't forget where you came from, if you honor the past and stay hopeful about the future, you can accomplish anything. As a boy growing up in Korea who dreamed of coming to the land of opportunity, I never could have imagined I would achieve so much."' The city of Houston designated August 15, 2014 as "Waun Ki Hong Day" by mayoral decree to celebrate the Festschrift of Lifetime Accomplishments of a Great Leader. ${ }^{2}$ Professor Hong loved baseball, especially the Red Sox. When he threw the first pitch at Fenway Park, which is the Red Sox's ball park, the city of Boston proclaimed May 22, 2015 as "Waun Ki Hong Day." Professor Hong often liked to use baseball terms when he talked to his colleagues and trainees. "Don't try to hit a home run at the start-just go for a small hit. In sports, you have to give credit to your teammates; it's the same in academia." ${ }^{1}$

AACR announced the AACR-Waun Ki Hong Award for Outstanding Achievement in Cancer Research. ${ }^{4}$ The award seeks not only to recognize a worthy cancer researcher who has conducted highly meritorious laboratory, translational, or clinical cancer research under the age of 46 years, but also to honor Professor Hong for his lifelong mentorship and support of the careers of young cancer researchers. In April 2017, at the AACR Annual Meeting in Washington, D.C., the first award was presented to Roger S. Lo, MD, PhD, a professor in the Division of Dermatology and an associate professor in the Department of Molecular and Medicinal Pharmacology at the David Geffen School of Medicine at the University of California, Los Angeles. Professor Hong said, "Aiming high and seeing the big picture. You have to ask yourself at the end of the day-are you proud of the thing you have done?"6 


\section{DEDICATION TO ALA MATER, SEVRANCE}

Professor Hong retired as the head of Cancer Medicine at the age of 72 years, but continued his important work with MDACC in a postretirement position within the Sheikh Khalifa Bin Zayed Al Nahyan Institute for Personalized Cancer Therapy and as part of the Advanced Scholar Program within Cancer Medicine. ${ }^{5} \mathrm{He}$ remains cherished as a mentor and an individual who left behind a legacy for us to appreciate. ${ }^{7}$ During his career, he trained more than 200 fellows from 18 countries, including China, Japan, Italy, France, and Spain. ${ }^{5}$ Most notably, he never forgot where he came from, and has given back so much to his homeland. As a result, more than 100 of his trainees were from Korea, with about 20 of them now acting as directors of cancer centers or leaders of cancer society in Korea. ${ }^{3}$ "Mentoring is my passion," said Professor Hong. "My era will soon be gone. You have to bring up the next generation of scientists and have a strong pipeline of talented people to succeed you; that results from mentorship."

Professor Hong worked hard with pride and integrity as a proud Korean-American, especially as a Yonsei University alumni. In 2000, he received an honorary D.M.Sc degree from Yonsei University with the Grand Prize in Medicine (Fig. 1). He has left a wonderful legacy at MDACC as a dedicated cancer researcher with a Korean heritage. To demonstrate his special affection toward his alma mater, starting in 2005, he led the External Advisory Board that culminated in the establishment of Yonsei Cancer Center. After being appointed as a special advisor to Yonsei University in 2014 to provide core strategies for Yonsei University and Yonsei Cancer Center,
Professor Hong shared the latest global trend of research and proposed its application plan for Yonsei University (Figs. 2 and 3). Moreover, he helped to train young researchers at his alma mater. He provided opportunities to students at Yonsei University and helped young medical scientists to gain experience at the MDACC, as well as full material and emotional support, to help them adapt to the new surroundings. ${ }^{4}$ Likewise, he visited his alma mater in 2017 and donated $\$ 100000$ worth of scholarship grants for medical students. His other key contributions to Severance Hospital included inviting Yonsei representatives to the GAP 2014 conference (an international conference attended by MDACC and its sister insti-

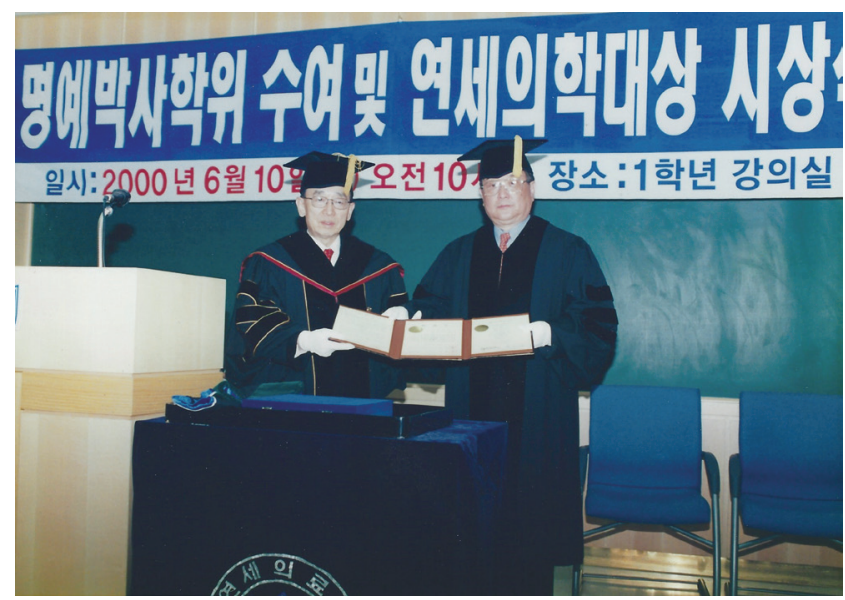

Fig. 1. In 2000, an honorary D.M.Sc degree was awarded to Professor Hong from his alma mater Yonsei University with the Grand Prize in Medicine.

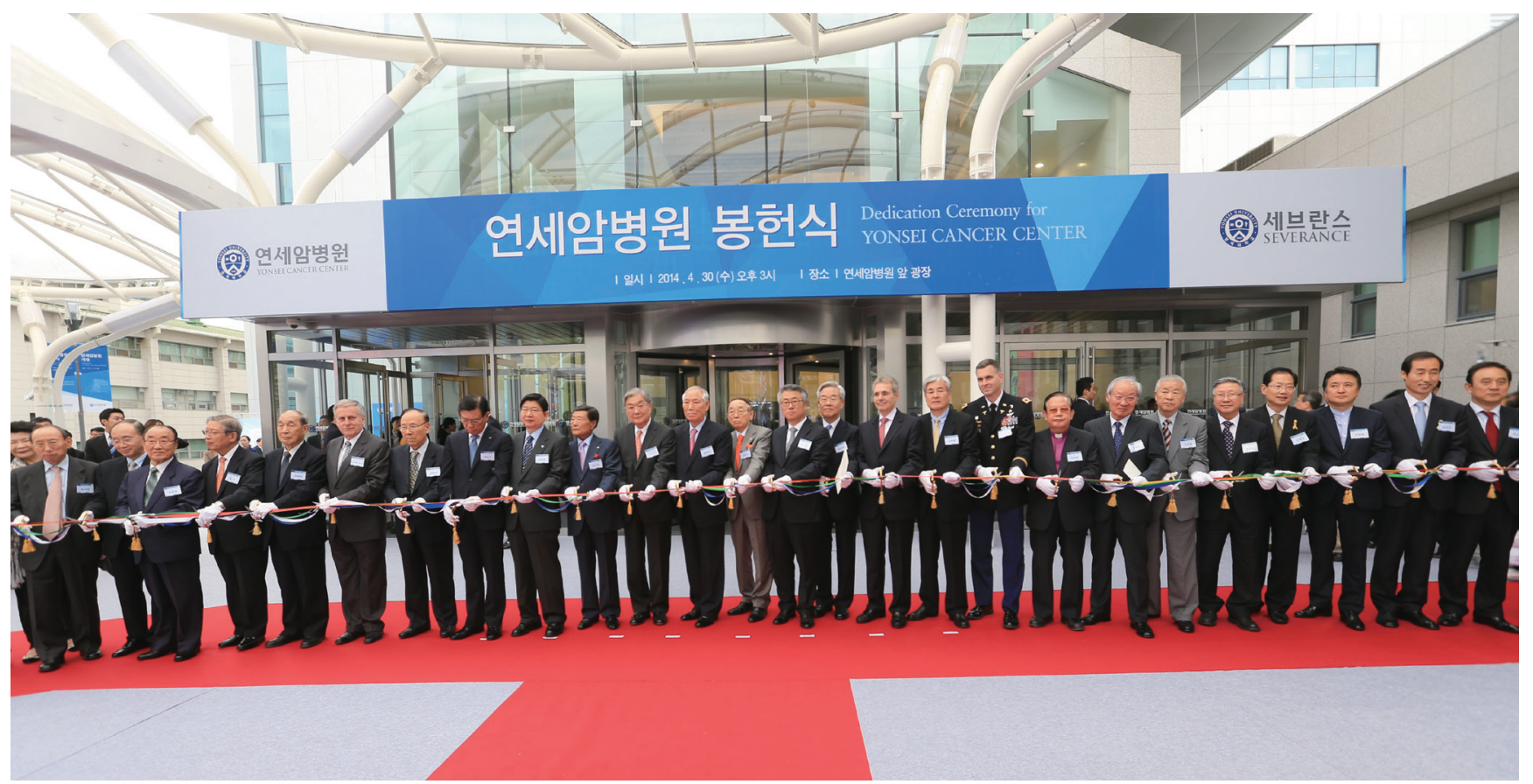

Fig. 2. Opening ceremony of the new Yonsei Cancer Center building. 


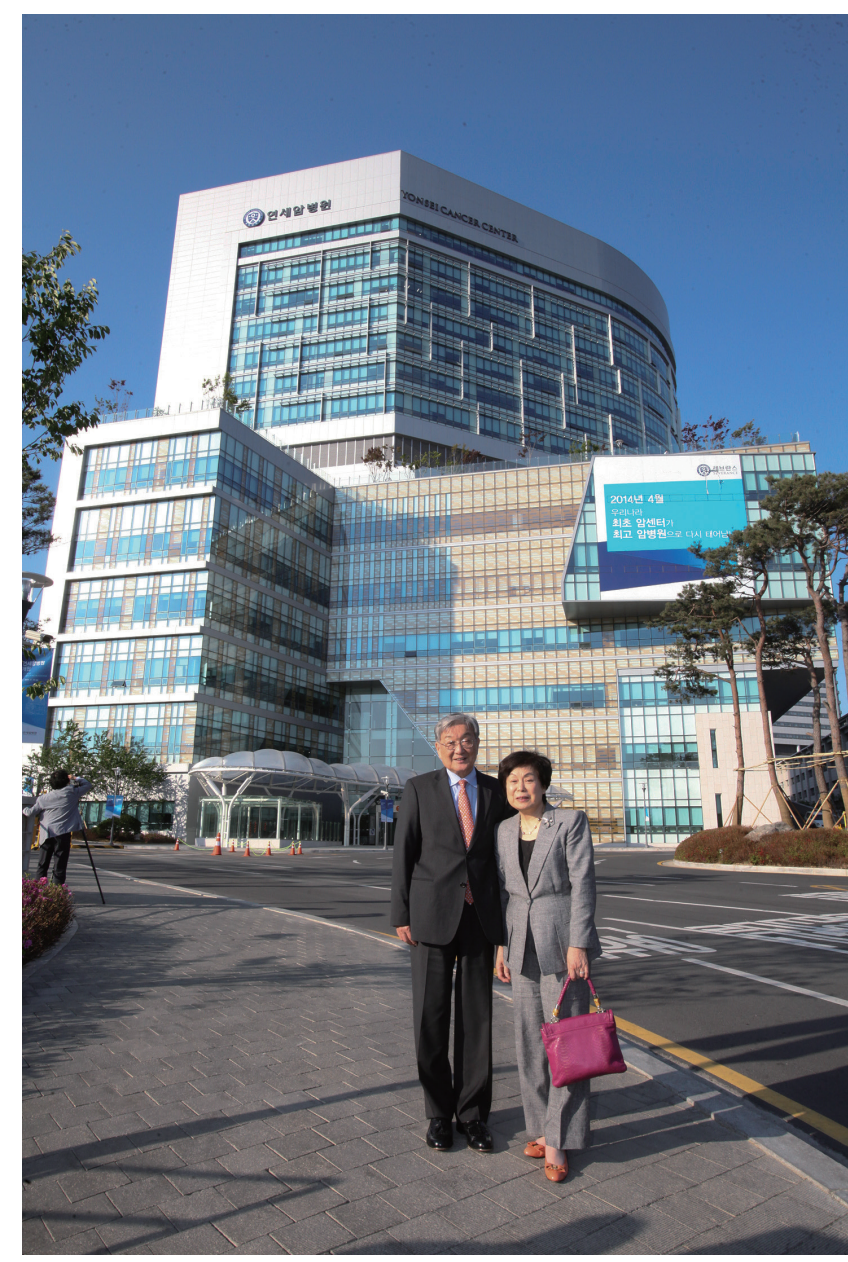

Fig. 3. Professor Hong visiting the new Yonsei Cancer Center building with Mrs. Hong. tutions), as well as allowing researchers from his alma mater to participate in the Sister Institution Network Fund (Fig. 4). In 2018, he helped establish the AACR-Korean Cancer Association (KCA) joint conference in Seoul. "Some people can be very smart but they can also be very selfish," he said. "Individuals are competent but they do not always know how to work together. A culture of collaboration and unselfishness should be cultivated among young people." ${ }^{8}$

Professor Hong passed away on January 2, 2019, at the age of 76 years. A memorial service was held at Onnuri Church in Newport, California on January 12, 2019 to celebrate his life. During his career, he built a colorful personal and professional resume throughout more than 50 years in academic medicine. His work has changed the lives of cancer patients on this planet. Given his career as a physician/scientist whose pioneering research has resulted in three groundbreaking contributions in cancer medicine, Professor Hong was posthumously awarded the Order of Civil Merit, Magnolia Medal from the Korean government, while the AACR-KCA decided to hold the Waun-Ki Hong Memorial Lecture at the AACR-KCA International Conference and Workshop beginning in 2019. The first lecturer of Waun-Ki Hong Memorial Lecture at the AACR-KCA workshop was Professor Roy H. Herbst of Yale Cancer Center. ${ }^{9}$ Professor Hong said he had achieved the American Dream. During his life, he helped many and left behind a legacy that will endure for generations. Professor Hong himself, a trailblazing pioneer and an international hero in the field of cancer medicine, is the embodiment of Cancer Medicine at MDACC and the Global Oncology Society. ${ }^{3}$

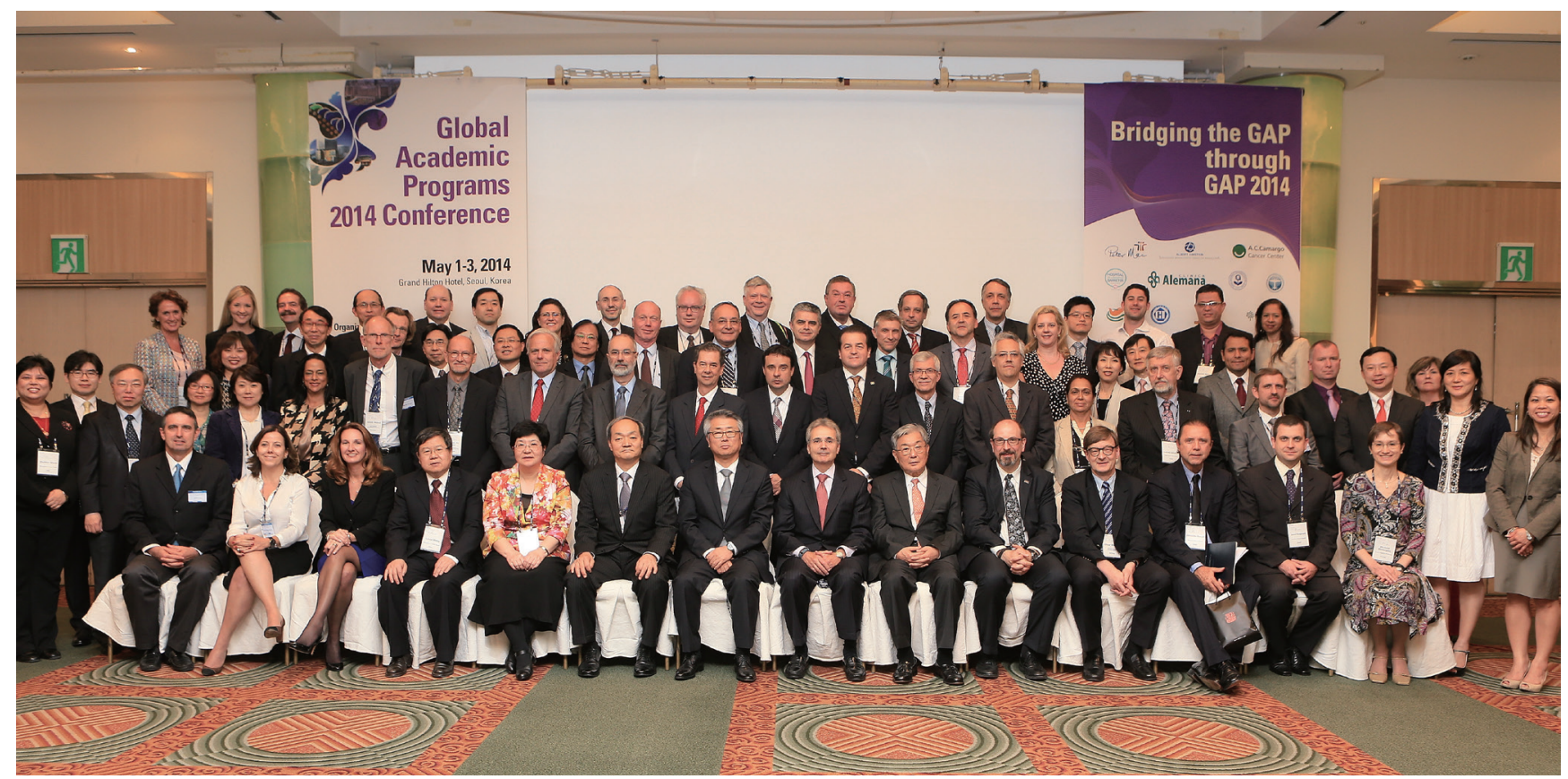

Fig. 4. Director's meeting of the Sister Institutions of Global Academy Program of MDACC. 


\section{ORCID iD}

Hyun Cheol Chung https://orcid.org/0000-0002-0920-9471

\section{REFERENCES}

1. Hong WK, Lemaistre CA. A cancer pioneer's personal and professional journey: a Korean American cancer researcher discusses his life's journey and the passion that spurred his success. Korean Korean Am Stud Bull 2003;13:118-33.

2. Khuri FR. A Titan exits stage left: summary of the Waun Ki Hong festschrift. Cancer 2015;121:2849-51.

3. Koh HK. Honoring Dr. Waun Ki Hong, a cancer pioneer and visionary: on the occasion of his festschrift, August 14, 2014. Cancer 2015;121:2852-6.
4. Paik JY. Dedication of life for cancer conquer. Yonsei University Alumni Association Newsletter 2016;506:9-9.

5. Cavallo J. Ushering in a new era in personalized medicine. The ASCO Post [Internet]. 2016 May 25 [accessed on 2020 February 20]. Available at: https://www.ascopost.com/issues/may-25-2016/ushering-in-a-new-era-in-personalized-medicine/.

6. American Association for Cancer Research. Dr. Waun Ki Hong reached the top and brought others with him. Leading Discoveries 2018:(1):2-6.

7. Watts G. Waun Ki Hong. Lancet 2019;393:2486.

8. Chu M. Korean-American oncologist offers valuable advice for physicians. Korea Biomedical Review [Internet]. 2018 May 24 [accessed on 2020 February 20]. Available at: http://www.koreabiomed.com/news/articleView.html?idxno=3342.

9. Kim HK. In memoriam: Waun Ki Hong, M.D. (August 13, 1942-January 2, 2019). Cancer Res Treat 2019;51:415-6. 